\title{
Detection of the Newcastle disease virus and its effect on development of post-vaccination immunity in a commercial flock of laying hens
}

\author{
Jana Jeřábková1, Růžena Juranová ${ }^{2}$, Kateřina Rosenbergová ${ }^{3,4}$, Libuše Kulíková2, \\ Alfred Hera ${ }^{1}$, Petr Lány ${ }^{3,4}$, Oldřich Kubíček ${ }^{4}$, Josef Koláček ${ }^{5}$
}

\author{
${ }^{1}$ Institute for State Control of Veterinary Biologicals and Medicines, Brno, Czech Republic \\ ${ }^{2}$ Avian and Exotic Animal Clinic, ${ }^{3}$ Department of Infectious Diseases and Epidemiology, \\ Faculty of Veterinary Medicine, University of Veterinary and Pharmaceutical Science Brno, Czech Republic \\ ${ }^{4}$ National Institute for Nuclear, Chemical and Biological Protection, Kamenna, Czech Republic \\ ${ }^{5}$ Company Proagro Nymburk a.s., department Opatovice, Czech Republic
}

Received March 31, 2011

Accepted February 14, 2012

\begin{abstract}
The aim of this study was to monitor the concentration of antibodies against Newcastle disease after vaccination of laying hens at the beginning and in the end of the laying period. The study was carried out in one commercial flock of laying hens in Opatovice in the Czech Republic in the years 2008-2010. A total of 280 samples of blood sera were taken from laying hens coming from four poultry houses. The sera were tested by the haemagglutination inhibition test according to the OIE Manual. Virological testing was conducted as a consequence of atypical results of serological testing. Newcastle disease virus RNA was proved by the RT-nested PCR method in the pooled tissue samples of 5 hens, in the samples of intestines with ileocaecal tonsila, in trachea and also in one swab sample from the environment of one house. Based on sequencing analysis and subsequent phylogenetic analysis, the virus was identified as a low pathogenic strain of paramyxovirus (PMV-1). This low pathogenic strain did not have any impact on the health of laying hens.
\end{abstract}

Poultry, antibodies, RT-nested PCR, sequencing

Newcastle disease (ND) is an infectious, highly contagious viral disease of the gallinaceous fowl affecting all age categories, caused by the Newcastle disease virus (NDV) belonging to the family Paramyxoviridae (PMV-1), genus Avulavirus. Viral genome is non-segmented, formed by a single stranded RNA with negative polarity (-ss RNA), coding for six proteins: NP - nucleoprotein, M - matrix protein, F - fusion protein, HN - haemagglutinin-neuraminidase protein, P - phosphorylated nucleocapsideassociated protein and L-RNA-dependent RNA polymerase (Kattenbelt et al. 2006). The virulence of the NDV is closely related to the variable cleavability of the F protein due to distinct amino acid composition of the "cleavage site" (Lee et al. 2004; de Leeuw et al. 2005). Studies comparing amino acid sequences of the F protein proved that strains which are virulent for poultry have the ${ }^{112} \mathrm{R} / \mathrm{K}-\mathrm{R}-\mathrm{Q}-\mathrm{K} / \mathrm{R}-\mathrm{R}-\mathrm{F}^{117}$ amino acid sequence at the "cleavage site", whereas low virulence strains have the ${ }^{112} \mathrm{G} / \mathrm{E}-\mathrm{K} / \mathrm{R}$ Q-G/E-R-L ${ }^{117}$ sequence in this area (Collins et al. 1993; Liu et al. 2003). Antigenic diversity of paramyxoviruses was confirmed in Australia between 1998-2000 (Annex to the EFSA Journal 2007).

Newcastle disease has a big socio-economic impact (Awan et al. 1994; Alexander 2000; Seal et al. 2000). Significant variability of clinical symptoms, which depends on the virulence of ND virus strains, is typical for this disease. Lentogenic virus strains cause only mild or no clinical symptoms, in particular in the adult birds, while the mesogenic strains cause higher mortality. Velogenic strains cause severe 
gastrointestinal, respiratory and/or nervous symptoms and mortality rate reaches almost 100\% (Banerjee et al. 1994).

Despite the antibody titres, infected hens excrete the virus via faeces; the virus is then transmitted transovarially into the eggs and infected chickens subsequently hatch from such eggs (Capua et al. 1993). The transmission of the NDV lentogenic strains were shown by Pospíšil et al. 1991 who detected the virus directly in the embryos of hatching eggs and in the intestinal contents of the non-vaccinated chickens up to 25 days after hatching, despite the fact that the parental flock was vaccinated and the specific maternal antibodies were present in the chickens. Newcastle disease virus disappeared from the chickens with no induction of the active production of antibodies; these chickens reacted to the vaccination by only very low and variable titres of antibodies.

The prevention mainly relies on flock protection from the appearance and spread of the infection into the flocks and on the specific ND immunoprophylaxis. The chickens are vaccinated using live vaccines usually $2-3 \times$, and around the age of 18 weeks they are revaccinated with inactivated vaccine with the aim to ensure the protection of laying hens until the end of the laying period. Cases of a lack of post-vaccination immunity against ND were reported in 2007 and 2008 despite these measures being in place. This led us to monitor the post-vaccination antibodies and to the virological testing of laying hens to identify the causes for the unusual development of post-vaccination immunity.

\section{Materials and Methods}

\section{Sample collection}

The monitoring of antibodies against ND was carried out in a commercial flock of laying hens in Opatovice in the Czech Republic. There were 9 poultry houses, from which 4 poultry houses (No. 2, 4, 8 and 10) has been chosen for monitoring. Three different types of the laying hybrid hens were kept in these poultry houses: the type Isa Brown in house No. 2 with the count of 40800 hens and in house No. 4 with the count of 26880 hens, the type Lohmann Brown-Lite in house No. 8 with the count of 42000 hens and the type Hisex brown in house No. 10 with the count of 62560 hens.

The chickens were vaccinated twice by the live vaccine against ND in 2007 and 2008 . The first vaccination by vaccine Avinew with strain VG/GA at 4 weeks of age and the second vaccination by the same vaccine in eight weeks of age (both live vaccines were administered in drinking water). In 2009, the first vaccination was done by the vaccine Avipro HB1 with the strain $\mathrm{HB} 1$ at 4 weeks of age; the second vaccination was done by the vaccine Avipro LaSota with the strain LaSota at 8 weeks of age (both live vaccines were administered in drinking water). Before the start of the laying period, at 14 weeks of age, the chickens were re-vaccinated by the inactivated vaccine against ND: vaccine Gallimune 302 ND-IB-EDS, ND strain Ulster 2C in the years 2007 and 2008 ; vaccine Cevac IB-ND-EDS K, ND strain LaSota in 2009).

In the years 2008-2010, a total of 280 blood samples were taken from the commercial laying hens and tested for the ND post-vaccination immunity. In 2008, the group of hens in house No. 4 was monitored during the laying period; 20 blood samples were taken at 23, 35, 53 and 71 weeks of age, a total 80 samples. In the same year, groups of hens from houses No. 2, 8 and 10 were monitored too; 20 blood samples were taken from each house at the beginning of the laying period (around the age of 20 weeks) and at the end of the laying period (around the age of 50 weeks). In 2009, the groups of hens from two poultry houses (No. 4 and 8 ) were monitored again; 20 blood samples were taken from each house at the beginning of the laying period and before the end of the laying period.

Haemagglutination inhibition test

The haemagglutination inhibition (HI) test was used for the detection of the presence of the antibodies against NDV according to the OIE Manual (2010). This laboratory work was done at the State Veterinary Institute Olomouc. Newcastle disease virus strain LaSota (originally from the vaccine Avipest) and NDV antiserum (VLA Weybridge, UK) was used for HI test.

Virological testing

The tissue samples from 5 randomly selected hens from house No. 4 were used for the virological testing. Brain, trachea, lungs, liver, kidney and caecum with ileocaecal tonsila were taken as the suspected organs. Five swab samples (one sample from the ceiling fan, one sample from the rear fan, one sample from the side fan and two samples from the feeders) from poultry house No. 4 were also taken in order to ensure a complete virological investigation. 
RNA extraction and Reverse transcriptase - nested polymerase chain reaction (RT-nested PCR)

Total RNA was isolated using RNeasy Mini Kit (Quiagen, Germany) according to the manufacturer's instructions. The F protein gene sequence (n. AY338284) acquired from the GenBank (NCBI) was used for RT- nested PCR development. Two sets of primers based on a conserved region of the F protein gene of NDV were designed. The sequence of a sense primer was 5'GAA AAA ACA CGG GTA GAA GA 3', the sequence of an antisense primer was 5'GAG CTG AGT TGG TTG TTC C 3' for the RT-PCR and 5'GTC AAC ATA TAC ACC TCA TCC CAG A $3^{\prime}$ and 5'GCA TTC TGG TTG GCT TGT ATC A $3^{\prime}$ for the nested PCR. The part of amplification product from nested PCR (298 bp) is a sequence of the "cleavage site". SYBR 1-STEP QRT-PCR kit for a one-step RT-PCR (Invitrogen, USA) was used with a 20-ml mixture under the following conditions: $0.4 \mathrm{ml}$ of RT/Taq Mix, $400 \mathrm{mM}$ (each) dNTP and $1.6 \mathrm{mM} \mathrm{MgCl}_{2}$. Reverse transcription was performed with $3 \mathrm{ml}$ of total RNA at $42^{\circ} \mathrm{C}$ for $50 \mathrm{~min}$. The PCR amplification programme consisted of 40 cycles of $94{ }^{\circ} \mathrm{C}$ for $35 \mathrm{~s}$, followed by $47{ }^{\circ} \mathrm{C}$ for $35 \mathrm{~s}$ and $72{ }^{\circ} \mathrm{C}$ for $90 \mathrm{~s}$. Finally, extension was at $72{ }^{\circ} \mathrm{C}$ for $5 \mathrm{~min}$. PPP Master Mix (Top Bio, Czech Republic) was used for nested PCR. PCR reaction was performed with $1 \mathrm{ml}$ of amplification product from RT-PCR. The PCR amplification programme consisted of 40 cycles of $94{ }^{\circ} \mathrm{C}$ for $35 \mathrm{~s}$, followed by $54{ }^{\circ} \mathrm{C}$ for $35 \mathrm{~s}$ and $72{ }^{\circ} \mathrm{C}$ for $60 \mathrm{~s}$. Finally, extension was at $72{ }^{\circ} \mathrm{C}$ for $5 \mathrm{~min}$. The amplified products after nested PCR were analysed by electrophoresis on a $2 \%$ agarose gel stained with ethidium bromide. The fragment size ( $298 \mathrm{bp})$ was compared with the DNA ladder (O'Gene Ruler ${ }^{\mathrm{TM}}$ DNA Ladder Mix, Fermentas, USA).

Sequencing of PCR product and phylogenetic analysis

The PCR product (298bp) was purified by QIAquick Gel Extraction Kit (Qiagen, Germany). The sequencing of PCR product nucleotides was performed in both directions with the help of capillary electrophoresis using a laserinduced phosphorescence detector and an automated genetic analyser "CEQ ${ }^{\text {TM }} 8000$ Genetic Analyzer" (Beckman Coulter, USA) at the Department of Biology and Wildlife Diseases, University of Veterinary and Pharmaceutical Science Brno, Czech Republic. Phylogenetic analysis was performed from the obtained nucleotide sequence of the $\mathrm{F}$ protein gene including the $\mathrm{F}_{0}$ "cleavage site" and deduced amino acid sequence compared with sequences in GenBank using AlignX program (Vector NTI, 5.5, INFORMAX, inc.)

\section{Results}

Houses No. 2 and 10

The post-vaccination immunity in hens from houses No. 2 and 10 showed the expected decline of antibodies towards the end of the laying period. Geometric mean of HI antibodies titres in hens from house No. 2 at the beginning of the laying period in October 2008 was 1323 , and 208 at the end of the laying period. Geometric mean of HI antibodies titres in hens from house No. 10 at the beginning of the laying period in February 2008 reached 1351 , and 181 at the end of the laying period.

\section{Houses No. 4 and 8}

Geometric mean of the HI titres of antibodies in hens from house No. 4 at the beginning of the laying period (June 2008) was 512 at the age of 23 weeks, 1024 at 35 weeks, 1448 at 53 weeks and 2048 at the end of the laying period at the age of 71 weeks. Geometric mean of HI titres of antibodies in the same house at the beginning of the laying period (July 2009) reached 2048 and 1403 at the end of the laying period. In house No. 8, geometric mean of HI titres of antibodies at the beginning of the laying period (July 2008) was 446 and 1448 at the end of the laying period. Geometric mean of $\mathrm{HI}$ titres of antibodies in the same house at the beginning of

Table 1. The results of the serological testing (haemagglutination inhibition test) of hens for Newcastle disease virus

\begin{tabular}{lcccc}
\hline & \multicolumn{4}{c}{ Geometric mean of HI titres of antibodies } \\
\cline { 2 - 5 } & $\begin{array}{l}\text { Start of the } \\
\text { laying period }\end{array}$ & $\begin{array}{l}\text { Midle of the } \\
\text { laying period }\end{array}$ & $\begin{array}{l}\text { End of the } \\
\text { laying period }\end{array}$ & $\begin{array}{l}\text { After the } \\
\text { laying period }\end{array}$ \\
\hline House No.2 (year 2008) & 1323 & - & 208 & - \\
House No.4 (year 2008) & 512 & 1024 & 1448 & 2048 \\
House No.4 (year 2009) & 2048 & - & 1403 & - \\
House No.8 (year 2008) & 446 & - & 568 & - \\
House No.8 (year 2009) & 446 & - & 181 & - \\
House No.10 (year 2008) & 1351 & - & &
\end{tabular}


the laying period (July 2009) was 446 and 568 at the end of the laying period. The results of the serological antibody testing of hens from houses No. 4 and 8 showed an unexpected increase in the antibody titres towards the end of the laying period. In house No. 4, only a slight decline was noted when tested repeatedly during the observation period. All results of the serological

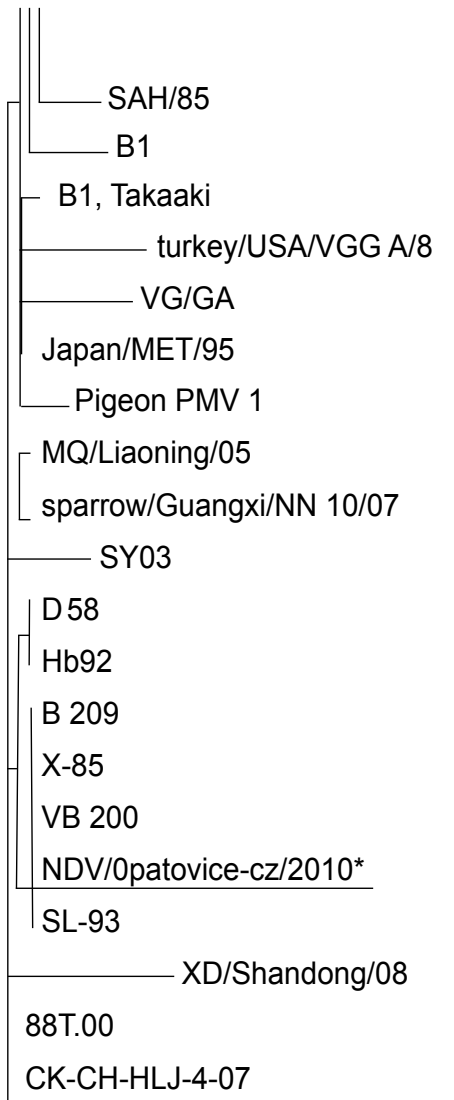

clone 30

$\mathrm{Hn} 0801$

LaSota

NDV038952

Qe01

SD-3-04-GO

SP 13

TYQ/Shanxi/07

$\mathrm{ZJ} / 2000$

Fig. 1. Phylogenetic analysis of the nucleotide sequence of the $\mathrm{F}$ protein gene of the low virulence Newcastle dísease virus (*our isolate). testing are in Table 1.

Newcastle disease virus was detected using RT-nested PCR in 3 pooled samples and in 4 samples of caeca with ileocaecal tonsilla and in two samples of trachea taken from the hens from house No. 4. The virus was not detected in any samples of the brain, lungs and liver. The virus was also detected in one swab sample of dust from the environment. The size of the PCR product was $298 \mathrm{bp}$.

The virus was identified as of low virulence, the "cleavage site" area contained the amino acid motive ${ }^{112} \mathrm{G}-\mathrm{R}-\mathrm{Q}-\mathrm{G}-$ $\mathrm{R}-\mathrm{L}^{117}$. The strain was named as NDV/Opatovice-cz/2010 (Fig. 1).

\section{Discussion}

The Institute for State Control of Veterinary Biologicals and Medicines started to provide random monitoring of post-vaccination antibodies against ND in some poultry flocks in order to verify the efficacy of the vaccination. The dynamics of the postvaccinational antibodies in hens from houses No. 2 and 10 showed a pattern similar to the one identified during the pre-authorisation field testing of certain inactivated vaccines, i.e. there was a decline in the antibody titres after the peak is reached at the age of approximately 30-35 weeks and, as a result, the antibody titre was lower at the end of the laying period but still provided protection. However, we could find also an atypical course of the post-vaccinational immunity in hens from poultry houses No. 4 and 8 , characterized by either only small decline or even an increase in the titre of the post-vaccinational antibodies with results reaching the value of up to 2048 when tested by the HIT. Laying hens housed in those houses were clinically healthy throughout the laying period. Similar observations were made by other authors in some other countries, e.g. in Italy (Capua et al. 1993).

The presence of a field paramyxovirus in hens was suspected when an unusual pattern of the postvaccinational immunity against ND was recorded. Randomly selected hens were sacrificed and dissected at the end of the laying period. Samples were taken from those animals for the RT-nested PCR testing to demonstrate the avian paramyxovirus. The brain, trachea, lungs, liver and caecum with ileocaecal tonsilla were taken as the suspected organs. Tests to detect the virus were at first carried out in mixed samples and, thereafter, 
in relevant organs as well as in samples of dust collected from different sites in the poultry house to detect the virus in the environment. PMV-1 was identified in the mixed organ samples of 5 hens, in the trachea and in the caecum with the ileocaecal tonsilla. PMV-1 was identified as a low virulent strain (named as NDV/Opatovice-cz/2010) with the amino acid motive ${ }^{112}$ G-R-Q-G-R-L ${ }^{117}$ (Collins et al. 1993; Kant et al. 1997; Gohm et al. 2000; Liu et al. 2003) by nucleotide sequencing of the "cleavage site" area in the sequence of the $\mathrm{F}$ protein gene. The strain is found in the phylogenetic tree at the branch common to the strains isolated in the 1990s by Pospíšil et al. (1991) from young chickens (X-85, VB-200, B-209 and SL-93) in the Czech Republic. The NDV/Opatovice-cz/2010 strain is also close to the LaSota and Clone 30 vaccination strains in the phylogenetic tree. This low virulence paramyxovirus was isolated from the environment of poultry house No. 4, and it spread in the flock by the aerogenous route. Neither health status nor productivity of the hens were affected by the strain, but it continuously stimulated the production of antibodies. In the case of our commercial laying hen farm, the presence of the low virulence paramyxovirus in the flock had a positive impact on the level and persistence of post-vaccination immunity throughout the laying period and helped to create a steady flock protection against ND with no impairment of the laying hens' productivity. When such situation occurs in the parent flock, the field strain can be transmitted to the offspring transovarially, resulting in the immunotolerance status followed by lower immune response to the vaccination in the affected offspring. The natural transovarial transmission of the NDV was repeatedly proved in the case of the parent flocks by virus isolation from the chicken embryos and from dayold chickens (Pospíšil et al. 1991; Capua et al. 1993), resulting in the impairment of the induction and level of the post-vaccinational immunity of the affected flock (Pospíšil et al. 1991). There is also a real risk with respect to the proved antigenic diversity (Annex to the EFSA Journal 2007) of a parallel infection by different ND virus strains in a host (vaccination and field strain) which may result in the origin of new NDV strains with variable pathogenicity.

This study demonstrated the presence of a low pathogenic strain of paramyxovirus (PMV-1) in the tissues of laying hens and also in the dust of poultry house. The presence of this virus stimulated immunity of hens against ND but had no negative impact on health and productivity of laying hens.

\section{References}

Alexander DJ 2000: Newcastle disease and other avian paramyxoviruses. Rev Sci Tech 19: 443-462

Annex to the EFSA Journal 2007. Available at: www.efsa.europa.eu. Accessed August 25, 2009

Awan MA, Otte MJ, James AD 1994: The epidemiology of Newcastle disease in rural poultry: a review. Avian Pathol 23: 405-423

Banerjee M, Reed WM, Fitzgerald SD, Panigraphy B 1994: Neurotropic velogenic Newcastle disease in cormorants in Michigan: pathology and virus characterization. Avian Dis 38: 873-878

Capua I, Scacchia M, Toscani T, Caporale V 1993: Unexpected isolation of virulent Newcastle disease virus from commercial embryonated fowls' eggs. J Vet Med B 40: 609-612

Collins MS, Bashiruddin JB, Alexander DJ 1993: Deduced amino acid sequences at the fusion protein cleavage site of Newcastle disease viruses showing variation in antigenicity and pathogenicity. Arch Virol 128: 363-370

Gohm DS, Thur B, Hofmann MA 2000: Detection of Newcastle disease virus in organs and faeces of experimentally infected chickens using RT-PCR. Avian Pathol 29: 143-152

Kant A, Koch G, Van Roozelaar DJ, Balk F, Huurne AT 1997: Differentiation of virulent and non-virulent strains of Newcastle disease virus within 24 hours by polymerase chain reaction. Avian Pathol 26: 837-849

Kattenbelt JA, Stevens MP, Gould AR 2006: Sequence variation in the Newcastle disease virus genome. Virus Res 116: $168-184$

de Leeuw OS, Koch G, Hartog L, Ravenshorst N, Peeters BP 2005: Virulence of Newcastle disease virus is determined by the cleavage site of the fusion protein and by both the stem region and globular head of the haemagglutinin-neuraminidase protein. J Gen Virol 86: 1759-1769

Lee YJ, Sung HW, Choi JG, Kim JH, Song CS 2004: Molecular epidemiology of Newcastle disease viruses isolated in South Korea using sequencing of the fusion protein cleavage site region and phylogenetic relationships. Avian Pathol 33: 482-491 
Liu XF, Wan HQ, Ni XX, Wu YT, Liu WB 2003: Pathotypical and genotypical characterization of strains of Newcastle disease virus isolated from outbreaks in chicken and goose flocks in some regions of China during 1985-2001. Arch Virol 148: 1387-1403

OIE 2008: Manual of diagnostic tests and vaccines for terrestrial animals, Newcastle disease: 576-589

Pospisil Z, Zendulkova D, Smid B 1991: Unexpected emergence of Newcastle disease virus in very young chicks. Acta Vet Brno 60: 263-270

Seal BS, King DJ, Sellers HS 2000: The avian response to Newcastle disease virus. Dev Comp Immunol 24: $257-268$ 